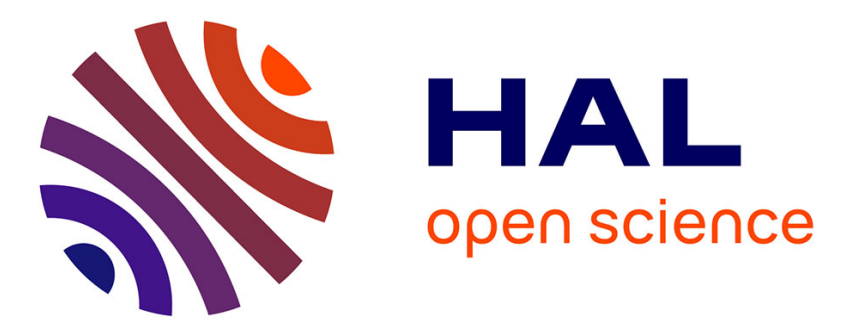

\title{
Impact of the French 3rd and 4th generation pill scare in women seeking termination of pregnancy
}

Ophélie Caillot, Marc Aubry, Solène Duros, Laurence Boyer, Claude van Valenberg, Jean Levêque, Vincent Lavoué

\section{- To cite this version:}

Ophélie Caillot, Marc Aubry, Solène Duros, Laurence Boyer, Claude van Valenberg, et al.. Impact of the French 3rd and 4th generation pill scare in women seeking termination of pregnancy. Journal de Gynécologie Obstétrique et Biologie de la Reproduction, 2017, 46 (1), pp.69-76. 10.1016/j.jgyn.2016.03.014 . hal-01308004

\section{HAL Id: hal-01308004 https://hal-univ-rennes1.archives-ouvertes.fr/hal-01308004}

Submitted on 8 Jul 2016

HAL is a multi-disciplinary open access archive for the deposit and dissemination of scientific research documents, whether they are published or not. The documents may come from teaching and research institutions in France or abroad, or from public or private research centers.
L'archive ouverte pluridisciplinaire HAL, est destinée au dépôt et à la diffusion de documents scientifiques de niveau recherche, publiés ou non, émanant des établissements d'enseignement et de recherche français ou étrangers, des laboratoires publics ou privés. 
Impact of the French 3rd and 4th generation pill scare in women seeking termination of pregnancy

Ophélie Caillot ${ }^{1,2}$, Marc Aubry ${ }^{3,4}$, Solène Duros ${ }^{1,2}$, Laurence Boyer $^{1}$, Claude Van Valenberg ${ }^{1}$, Jean Levêque ${ }^{1,2,5}$, Vincent Lavouéé

1, Rennes University Hospital, Department of Gynecology, Hôpital Sud, 16, Bd de Bulgarie, 35700 Rennes. France

2, University of Rennes 1, Faculty of Medicine

3, University of Rennes 1, UEB, UMS 3480 Biosit, Faculty of Medicine, Rennes F-35043, France

4, Environmental \& Human Genomics Facility, University of Rennes 1, Rennes F-35043, France

5, ER 440, OSS, INSERM

\section{Corresponding author:}

\section{Pr Vincent Lavoué}

Service de Gynécologie -Obstétrique - 16 boulevard de Bulgarie - CHU Rennes, FRANCE.

Vincent.lavoue@chu-rennes.fr

All authors were funded by Teaching Hospital of Rennes.

Authors have no conflict of interest.

Word count of the abstract: 170 words

Word count of the test: 2599 words

Keywords: Pill, Contraception, Pill scare, Abortion, Long-Acting Reversible Contraception

Running title: the French 3rd and 4th generation pill scare 


\begin{abstract}
Introduction: The aim of this study was to evaluate changes in the contraceptive profile of women seeking termination of pregnancy following the debate on 3rd and 4th generation pills in France in 2012.

Materials and Methods: Single-center case-control study comparing the attitude to contraception before (between 02/15/2012 and 07/16/2012) and after the debate (between 02/25/2013 and 06/24/2013).

$\underline{\text { Results: }}$ A total of 291 patients consulted before and 601 after the debate. We showed that there were more students $(+9.5 \%)$, more single women $(+8.3 \%)$ and fewer working women $(-7.7 \%)$ in the cohort after the debate. After the termination procedure, prescriptions for long-acting reversible contraceptive (LARC) methods increased $(+7.8 \%, \mathrm{p}=0.03)$, in particular in patients aged 25 or younger including nulliparous $(+12.6 \%, \mathrm{p}=0.02)$.

Conclusion: The media alert about the pill led to a change in the contraceptive standard in the postabortion period and altered patient profiles. An increase was notably observed in certain vulnerable populations (high school students, unemployed and single women). It remains to be seen whether these changes are transient or permanent.
\end{abstract}




\section{INTRODUCTION}

France is characterized by a model of contraception that is heavily medicalized in which the pill holds a dominant place (1). The French contraceptive landscape shows a high level of theoretical efficiency, yet the number of pregnancy terminations is high, amounting to $14 \%$ (2) (3). Since 2007, the French National Authority for Health (HAS) has recommended that 3rd and 4th generation pills no longer be prescribed due to increased risk of thromboembolism compared with second-generation pills (4). However, 3rd and 4th generation pills have been partially reimbursed since 2009. At the end of 2011, the increased thromboembolism risk associated with 3rd and 4th generation pills was confirmed twice by Lidegaard et al. (5) and HAS proposed to stop reimbursing these pills in September 2013. Besides, on December 14, 2012, a leading daily newspaper published the headline "Warning about the pill" following a complaint lodged by a young woman who suffered a stroke due to the use of 3rd generation pills (6). There was subsequently intense debate in the French media about the risk with these last-generation pills. The decision to stop reimbursing 3rd and 4th generation pills was brought forward to March 2013, leaving women with less than 6 months to see their healthcare professional in order to change contraception.

The FECOND survey was repeated in 2013 (7) to examine the latest trends in contraception in France and particularly to assess the impact of the pill scare on the contraceptive practices of the general population. In particular the survey reported a change in the contraceptive model. The number of terminations increased by $5 \%$ following the debate (8) and it is interesting to consider the change in the contraceptive profile of the population seeking to terminate their pregnancy. Our main objective was to study the impact of the debate about 3rd and 4th generation pills on the contraceptive practices of women seeking termination of their pregnancy by comparing their stated method of contraception before and after the debate. 


\section{MATERIALS AND METHODS}

\section{Design}

We conducted a single-center case-control study in the pregnancy termination clinic at Rennes Teaching Hospital. The study group consisted of patients seeking a termination of pregnancy after the debate, between $02 / 25 / 2013$ and $05 / 15 / 2013$. The control group consisted of patients recruited before the debate, between $05 / 15 / 2012$ and 07/16/2012. The inclusion criteria were women seeking a termination of pregnancy during the inclusion periods. The exclusion criteria were patients with missing contraceptive data. Electronic patient files were used to collect the data which was then compiled into anonymous Excel® files. The study was approved by the Institutional Review Board of the French College of Obstetricians and Gynecologists (CEROG-2011-GYN-08-03).

\section{Collected data}

Data were collected in a retrospective manner. They included: sociodemographic data (age, country of birth, marital status, professional status, education level), medical and surgical information, gynecological history (gravidity, parity, pregnancy termination history, miscarriage, ectopic pregnancy, pelvic infection, latest Pap smear, vaccination against Human Papillomavirus) and data on termination of pregnancy (term, complications, post-abortion consultation, partner's opinion). We also collected data on the contraceptive method used, which was stated before and after the termination procedure. Contraceptive methods were classified into medical and non-medical methods. The medical methods were divided into 4 categories: 1) oral contraception (combined or progestin-only pill), 2) contraceptive skin patch and vaginal ring, 3) long-acting reversible contraceptive methods (LARC) represented by the intrauterine device (IUD) and the contraceptive implant, and 4) permanent methods with tubal ligation. The non-medical methods were divided into two categories: the natural contraception (mainly withdrawal and Ogino-Knaus methods) and the barrier methods (condoms and spermicide). 


\section{Statistical analysis}

Statistical analyses were conducted using Chi-Square tests or Fisher's exact tests, as appropriate, to compare proportions, while Student's $t$ test was used for comparison of quantitative variables as means and standard deviations. We used $\mathrm{R}$ software version 3.1.2. $P \leq 0.05$ was considered significant. 


\section{RESULTS}

During the study periods before and after the debate, 910 patients seeking abortion consulted with the pregnancy termination clinic. Eighteen patients were excluded from the study due to incomplete contraception data. A total of 892 patients were included of which 291 patients for the first period before the media debate on the 3rd and 4th generation pill (control cohort). There were 619 patients for the second period after the debate (study cohort).

\section{Description and comparison of populations (Table 1)}

The average age was 27.6 years $(+/-0.4)$ and 27.0 years $(+/-0.3)$ before and after the pill debate respectively (NS). We found a greater number of single women in the cohort after the debate, rising from $40.1 \%$ to $48.4 \%(\mathrm{p}=0.02)$ and a fall of $8 \%$ for women who were married or with partners $(\mathrm{p}=0.002)$. In the case of working women, $58.7 \%$ were employed before the debate as against $51 \%$ afterwards $(\mathrm{p}=0.04)$. The number of students rose after the debate: $17.4 \%$ versus $26.9 \%$, respectively ( $\mathrm{p}=0.003$ ). Primigravida and nulliparous women were similar in the two groups: $36.3 \%$ versus $37.8 \%$ and $49.8 \%$ versus $50.6 \%$, respectively. The proportion of primigravida women was higher after the debate: $20.1 \%$ as against $15.2 \%$, marking a significant trend $(\mathrm{p}=0.1)$. The previous abortion rate was similar in the two groups: $31 \%$ versus $35.9 \%$ before and after the debate, respectively (NS). The average term of abortion was $8.8(+/-0.1)$ weeks' gestation before and after the debate: $18.2 \%$ versus $23.9 \%$, although the statistical significance threshold was not reached $(\mathrm{p}=0.08)$.

\section{Contraceptive method used before and after pill debate}

Data on contraceptive methods used before abortion are shown in Table 2. Before the debate, 58.4\% of patients used contraception versus $52.4 \%$ after the debate $(\mathrm{p}=0.1)$. Among the women using medical contraception, the rate of pill users declined after the debate: $32.6 \%$ versus $26.2 \%(\mathrm{p}=0.1)$. 
Data on contraceptive methods used after abortion are shown in Table 3. Almost all women used contraception before and after the debate: $98.2 \%$ and $97.2 \%$ of patients, respectively. The proportion of women choosing effective medical contraception did not change: $96.5 \%$ before and 95.4\% after the debate $(\mathrm{p}=0.5)$. Among the women using medical contraceptive methods, there was a significant decline in pill use: $48.8 \%$ before the debate and $41.6 \%$ afterwards $(\mathrm{p}=0.05)$. There were mainly fewer combined oral contraceptive pill users (45.4\% versus $38.8 \%)$. On the other hand, the number of LARC users increased from $42.9 \%$ to $50.7 \%$ ( $\mathrm{p}=0.03$ ). The majority of post-abortion patients opted for a LARC method after the debate. The proportion of IUDs (intrauterine devices) immediately post abortion increased from $27.8 \%$ to $32.6 \%(\mathrm{p}=0.2)$ before and after the debate respectively. The proportion of contraceptive implants increased by $3 \%$ after the debate $(\mathrm{p}=0.3)$.

\section{Analysis of the subgroup of patients using LARC post abortion (Table 4)}

The increase in the number of LARC users in the post-abortion period involved mostly patients under 25 years of age. The proportion of women under 25 years of age using LARC increased from $28 \%$ to $40.6 \%(\mathrm{p}=0.02)$, when comparing before and after the debate, respectively, particularly in nulliparous women (rising from $29 \%$ to $41.6 \%(\mathrm{p}=0.017)$ ). We also observed an increase in IUD use among women having their first abortion: from $53.6 \%$ to $64.9 \%$ ( $\mathrm{p}=0.03$ ), when comparing before and after the debate.

\section{DISCUSSION}

To our knowledge, this is the first study to examine the impact of the debate over the 3rd and 4th generation pill (referred to as the French "pill scare") on the contraceptive use of patients seeking abortion. We showed that there was a diversification in contraceptive practices after the debate about the 3rd and 4th generation pill, particularly after abortion. After the debate, the use of pillbased contraceptive methods declined by $7.2 \%(\mathrm{p}=0.05)$ to the benefit of LARC methods which 
increased by $7.8 \%(p=0.03)$ after abortion, especially the IUD. This was the option chosen in particular by women of 25 years or younger $(+12.6 \%, \mathrm{p}=0.02)$ including nulliparous women $(+12.6 \%, \mathrm{p}=0.01)$. The French pill scare about 3rd and 4th generation pills led to a change in contraceptive practices in young and/or nulliparous women. We showed a higher proportion of patients aged 20 to 29 years $(+7 \%, \mathrm{p}=0.03)$ and also of patients with no steady partner $(+8.3 \%$, $\mathrm{p}=0.02$ ). These findings seem logical because this population is used to taking combined oral contraceptive pills according to the French model (7) and, following the pill scare, use of these oral contraceptives fell, exposing the patients to unintended pregnancies.

In France, oral contraceptive use is still predominant with $50.6 \%$ of users in 2012. LARC methods are the second favorite methods with $20.7 \%$ of IUD users, mainly women over 35 years of age (9) (10). Two thirds of induced abortions occur in women using contraception. In 2010, the FECOND survey assessed issues of reproductive and sexual health, showing a slight shift away from oral contraception $(-4.6 \%)$ between 2000 and 2010. In the survey repeated in 2013, this effect was shown to be greater after the debate. In our study, the number of post-abortion pill users fell after the pill scare. In our population, LARC use increased by $7.8 \%(\mathrm{p}=0.03)$ with a majority of IUDs $(64.2 \%)$ after induced abortion. This is in line with the observation of a $22 \%$ rise in IUD sales by the French National Agency for Medicine and Health Product Safety (ANSM) (11). Contrary to the FECOND survey, we did not find an increase in non-medical methods, probably due to the limited power of our study (7). The sharp increase in LARC use among women aged under 25 and nulliparous women showed a personal move to a less burdensome contraceptive method. The FECOND survey also observed this increase in LARC use in younger women: $+8 \%$ in women of 25 to 29 years and $+3 \%$ in those of 20 to 24 years. The French contraceptive model (condoms at sexual debut, pill until wanted pregnancies, and IUD after all wanted pregnancies) remains predominant in France. This model failed particularly among younger and single women and women with no steady partner (12) (13). LARC methods seemed suitable for this population with a continuation rate of $85 \%$ as against $68 \%$ for the pill (14). The debate appears to have changed the French contraceptive 
landscape and increased the number of abortions. Whether this increase will be transient or not remains to be seen. This change also came after several years of reluctance on the part of healthcare professionals to prescribe IUDs to nulliparous women (15) (16). Despite the national HAS guidelines, IUD prescriptions did not increase until 2010 (7) although the devices were recommended as first-line contraception like combined oral contraceptive pills. Fear of pelvic inflammatory disease and painful insertion limited the use of LARC methods in nulliparous women (17). Many publications have reported the lack of any risk of infection or infertility with IUD use (18) (19) (20). Moreover, LARCs are an attractive option for reducing the number of unintended pregnancies and therefore the number of induced abortions (21). According to a recent American prospective study known as the Contraceptive CHOICE Project, IUD use reduced the proportion of unintended pregnancies from $15.8 \%$ to $3 \%$ and voluntary terminations from $4.1 \%$ to $0.9 \%$ (22). In our study, physicians' attitudes towards contraception seemed to be changed: they prescribed more IUDs after the debate according to the increased sales figures (+22\%) in the French general population (ANSM) (11).

In 1995, numerous articles accused the 3rd generation pill of increasing thromboembolic risk compared to second-generation pills. Despite ANAES (French national health accreditation and evaluation agency) guidelines advocating the use of IUDs, the pill remained the first line of prescription (23) (24), with more than 2 million French users towards the end of 2011. In 2010, one in two women was prescribed a 3rd or 4th generation pill that was partly reimbursed in 2009 (7) (23). The pharmaceutical laboratories continued to promote it, arguing that these pills caused less weight gain and treated acne. Danish publications on 3rd and 4th generation pills stimulated the debate. However, the change in contraceptive behavior occurred only after a highly publicized lawsuit over a stroke in a young woman in December 2012. The decision promptly taken by the French government to stop reimbursing 3rd and 4th generation pills heightened women's anxiety whereas thromboembolic risk was lower for pill users than for pregnant women: 6/10000 as against 4/10000 (23) (25) (26). The French Department of Health advised not to panic or suddenly 
discontinue contraception just one month after the lawsuit was filed (27). Pozzi et al. examined the impact of the "pill alert" on the number of elective abortions in four pregnancy termination clinics in Paris (8). From February 2013 to April 2013, they observed a 4\% increase in the number of induced abortions, an observation also confirmed by a national survey (7). The French government made the same mistake as was made during the 1995 British "pill scare" when elective abortions rose by $8 \%$ during the following year, particularly in women under the age of 20 . In our study, the debate mainly had an impact on patients of 20-29 years old with $7 \%(\mathrm{p}=0.03)$ more patients seeking induced abortion. At the sexual debut of these women, the pill was central to the French contraceptive model (7). Moreover, women in disadvantaged social groups (pupils, students or women in vocational training) were the most exposed (28). In our study, the proportion of women who sought to terminate their pregnancy was already high before the debate but it increased to a worrying level after the debate $(+9.3 \%, \mathrm{p}=0.003)$. Public acceptance appeared to differ between social groups, as N. Bajos (7) and I. Nisand (25) reported that the information seemed to have been perceived as clearer but also more alarming by the less affluent socioprofessional categories. The emergency measures taken by the health authorities caused much anxiety which was disproportionate to the real risk. The message advising users not to discontinue contraception had not been heard and came too late. Induced abortion was considered less of a risk than contraception. Although national advertising campaigns did not change the French contraceptive landscape in 2007 and 2010, the French pill scare led to a change in contraceptive use (fewer combined contraceptive pills and more LARC) in France but with a higher number of induced abortions, particularly among the most vulnerable (26).

\section{Study limitations}

Our study has certain limitations. First of all, this is a retrospective case-control study that is limited by its lack of information and heterogeneous data gathering methods. However, it reflects the daily reality of a pregnancy termination clinic and shows the positive and negative impact of the media debate over 3rd and 4th generation pills. There appears to be a negative impact on the population 
that used combined oral contraceptive pills: mostly single women of 20-29 years. These women had unexpectedly discontinued their contraception, resulting in a higher rate of induced abortion. On the other hand, there was a change in the use of LARC methods, notably IUDs, following a medical discussion after induced abortion. We also believe that the French pill scare will result in a change in physicians' contraceptive prescription habits.

\section{CONCLUSION}

The French pill scare caused anxiety that led to an increase in the abortion rate, in particular among women in vulnerable situations, such as students $(+9.5 \%, \mathrm{p}=0.03)$ and single women $(+8.3 \%$, $\mathrm{p}=0.02)$. Our study showed a $7.8 \%(\mathrm{p}=0.03)$ increase in LARC prescription in post-abortion patients after the debate. IUDs were preferred, notably by women aged 25 or younger, including nulliparous women, for whom an increase of $12.6 \%(\mathrm{p}=0.02)$ was seen after induced abortion. After the French pill scare, patients and health practitioners opted for contraception with no thromboembolic risk and less risk of unintended pregnancy. Nevertheless, it is unfortunate that the first elective abortion was necessary for these patients to be prescribed appropriate contraception. Serious consideration of an effective primary prevention strategy for unintended pregnancy prevention should be undertaken, with a particular focus on teenagers in the hope of impacting their adult life.

\section{CONFLICT OF INTEREST}

The authors have no conflict of interest to declare.

Acknowledgment: Acknowledgment is due to Tracey Westcott for editing the draft. All authors were funded by Teaching Hospital of Rennes. 


\section{REFERENCES}

1. INPES. Contraception : Les Françaises utilisent-elles un contraceptif adapté à leur mode de vie ? 2011.

2. DREES. Les interruptions volontaires de grossesse en 2013. http://www.drees.sante.gouv.fr/lesinterruptions-volontaires-de-grossesse-en-2013,11504.html

3. Bajos N., et al. Why has the number of abortions not declined in France over the past 30 years? Popul Soc (Paris) 2004; 407.

4. Haute Autorité de Santé. Réévaluation des contraceptifs oraux de 3ème génération; 2007.

5. Lidegaard O, Nielsen LH, Skovlund CW, Skjeldestad FE, Lokkegaard E. Risk of venous thromboembolism from use of oral contraceptives containing different progestogens and oestrogen doses: Danish cohort study, 2001-9. BMJ 2011;343: 6423-6423.

6. Rollot C. December 14, 2012: Marion Larat lance l'alerte sur la pilule (Marion Larat launches the pill alert). Le Monde. http://www.lemonde.fr/festival/article/2014/07/29/14-decembre-2012marion-larat-lance-l-alerte-sur-la-pilule_4464213_4415198.html

7. Bajos N. et al. Enquête Fécond. La crise de la pilule en France: vers un nouveau modèle contraceptif? Popul Soc (Paris) 2014; 511.

8. Pozzi-Gaudin S, Deffieux X, Davitian C, Guerre N, Faucher P, Bacle F, et al. Impact of media alerts on contraceptive pills medication. J Gynecol Obstet Biol Reprod (Paris); 2014.

9. Bajos N. et al. Enquête Fécond. La contraception en France: nouveau contexte, nouvelles pratiques ? Popul Soc (Paris) 2012; 492.

10. Haute Autorité de Santé. Etats des lieux des pratiques contraceptives et des freins à l'accès et au choix d'une contraception adaptée ; 2013. 
11. ANSM. Evolution de l'utilisation en France des Contraceptifs Oraux Combinés (COC) et autres contraceptifs de décembre à mai 2013; 2013.

12. INPES. Contraception: que savent les Français? Connaissances et moyens de contraception : état des lieux ; 2007.

13. Nisand I. How could the number of abortions in France be reduced? Gynécologie Obstétrique Fertil 2003;31:499-503.

14. Guicheteau C.et al. Tolérance du dispositif intra-utérin au cuivre chez les patientes nullipares : étude prospective unicentrique. Gynécologie Obstétrique Fertil 2015; 43:144-50.

15. Moreau C, Bajos N, FECOND group. Estimates of unintended pregnancy rates over the last decade in France as a function of contraceptive behaviors. Contraception 2014; 89:314-21.

16. Moreau C, Bohet A, Hassoun D, Teboul M, Bajos N. Trends and determinants of use of longacting reversible contraception use among young women in France: results from three national surveys conducted between 2000 and 2010. Fertil \& Steril 2013; 100:451-8.

17. Moreau C, Bohet A, Hassoun D, Ringa V, Bajos N, FECOND group. IUD use in France: women's and physician's perspectives. Contraception 2014; 89:9-16.

18. Hubacher D. et al. Use of copper intrauterine devices and the risk of tubal infertility among nulligravid women. N Engl J Med 2001; 345:561-7.

19. Mohllajee AP, Curtis KM, Peterson HB. Does insertion and use of an intrauterine device increase the risk of pelvic inflammatory disease among women with sexually transmitted infection? Contraception 2006; 73:145-53.

20. Berenson AB, Tan A, Hirth JM, Wilkinson GS. Complications and continuation of intrauterine device use among commercially insured teenagers. Obstet Gynecol 2013; 121(5):951-8. 
21. Peipert JF, Madden T, Allsworth JE, Secura GM. Preventing unintended pregnancies by providing no-cost contraception. Obstet Gynecol 2012; 120:1291-7.

22. Mestad R, Secura G, Allsworth JE, Madden T, Zhao Q, Peipert JF. Acceptance of long-acting reversible contraceptive methods by adolescent participants in the Contraceptive CHOICE Project. Contraception 2011; 84:493-8.

23. Emmerich J, Thomassin C, Zureik M. Contraceptive pills and thrombosis: effects of the French crisis on prescriptions and consequences for medicine agencies. Thromb Haemost 2014;12:1388-90.

24. ANAES. Stratégies de choix des méthodes contraceptives chez la femme. Recommandations pour la pratique clinique; 2004.

25. Nisand I. Abortions have actually increased in France in 2013. Gynécologie Obstétrique Fertil $2015 ; 43: 1-2$.

26. Mazuy M et al. Le nombre d'IVG est stable mais moins de femmes y ont recours. Population-F 2014; 69: 365-398.

27. Furedi A. The public health implications of the 1995 "pill scare". Hum Reprod Update 1999; $5: 621-6$.

28. Blumenthal PD, Voedisch A, Gemzell-Danielsson K. Strategies to prevent unintended pregnancy: increasing use of long-acting reversible contraception. Hum Reprod Update 2011;17:121-37. 


Characterist

Age (years)
$<20$
$20-24$
$25-29$
$30-35$
$35-39$
$\geq 40$

\section{Marital status}

Married/civil partnership

De facto union

Divorced or separated

Single

\section{Country of birth}

France

Other

\section{Professional status}

Employed

High school/Student/Training

Unemployed

Housewife

\section{Education level}

Primary/Middle school

High school

University

\section{Smoking \\ Yes \\ No}

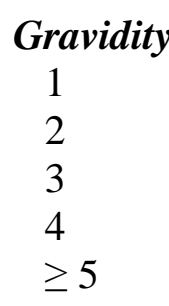

\section{Parity}

0

1

2

$\geq 3$
Before debate

$\mathrm{n}=\mathbf{2 9 1}$

(\%)

$$
\begin{gathered}
39(13.4 \%) \\
79(27.1 \%) \\
56(19.2 \%) \\
56(19.2 \%) \\
43(14.8 \%) \\
18(6.2 \%)
\end{gathered}
$$

$$
55(19.5 \%)
$$

$94(33.3 \%)$

$20(7.1 \%)$

$113(40.1 \%)$

$232(82.3 \%)$

$50(17.7 \%)$

$165(58.7 \%)$

$49(17.4 \%)$

$54(19.2 \%)$

$13(4.6 \%)$

$56(19.9 \%)$

$111(39.5 \%)$

$114(40.6 \%)$

$168(58.1 \%)$

$121(41.9 \%)$

$$
\begin{gathered}
105(36.3 \%) \\
49(17 \%) \\
51(17.6 \%) \\
29(10 \%) \\
55(19 \%)
\end{gathered}
$$

$144(49.8 \%)$

$44(15.2 \%)$
After debate $\mathrm{n}=\mathbf{6 0 1}$

(\%)

p-

value

$78(13 \%)$

0.9

$186(30.9 \%)$

0.3

$134(22.3 \%)$

0.4

$100(16.6 \%)$

0.3

$74(12.3 \%)$

0.6

$29(4.8 \%)$

0.6

$\begin{array}{cc}69(11.6 \%) & \mathbf{0 . 0 0 2} \\ 181(30.4 \%) & 0.4 \\ 57(9.6 \%) & 0.3 \\ 286(48.4 \%) & \mathbf{0 . 0 2}\end{array}$

$515(86.6 \%)$

0.12

$80(13.4 \%)$

0.12

$304(51.1 \%)$

0.04

$159(26.7 \%)$

$114(19.5 \%)$

$16(2.7 \%)$

0.003

1

0.2

0.4

0.02 


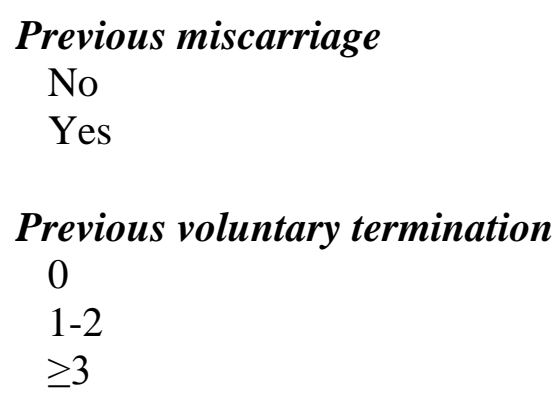

Term of abortion

$$
\begin{aligned}
& \text { 5-6 WG } \\
& 7-8 \mathrm{WG} \\
& 9-10 \mathrm{WG} \\
& 11-12 \mathrm{WG} \\
& 13-14 \mathrm{WG}
\end{aligned}
$$

$57(19.7 \%)$

$44(15.2 \%)$

$242(83.7 \%)$

$47(16.3 \%)$

$186(64.1 \%)$

$94(32.4 \%)$

$10(3.4 \%)$

$53(18.2 \%)$

$114(39.2 \%)$

$80(27.5 \%)$

$30(10.3 \%)$

$14(4.8 \%)$
$104(17.3 \%)$

$73(12.1 \%)$

0.4

0.2

$505(84 \%)$

0.9

$96(16 \%)$

0.9

$412(69.1 \%)$

0.2

$179(29.8 \%)$

$7(1.2 \%)$

0.4

0.038

$142(23.6 \%)$

$236(39.3 \%)$

$153(25.5 \%)$

$45(7.5 \%)$

$25(4.2 \%)$
0.08

1

0.6

0.2

0.8

WG = weeks of gestation 
Table 2. Pre-abortion contraceptive methods used before and after debate

Pre-abortion contraception

Before debate

(\%)

$\mathbf{n}=\mathbf{2 9 1}$

Contraception

Type of contraception

Medical contraception
Yes

No

Medical

Non-medical

Barrier

Natural

Oral

LARC

Patch/Ring

Other (Tubal

ligation)

$170(58.4 \%)$

$121(41.6 \%)$

$102(35 \%)$

$68(23.4 \%)$

$64(22.3 \%)$

$4(1.4 \%)$

$95(32.6 \%)$
$4(1.4 \%)$
$3(1 \%)$
0

$85(29.2 \%)$

$10(3.4 \%)$

Combined
Progestin only

Oral contraception

$147(24.5 \%) \quad$ NS $(0.1)$

$16(2.7 \%) \quad$ NS $(0.6)$

LARC

$\begin{array}{lccc}\text { IUD } & 4(1.4 \%) & 8(1.3 \%) & \text { NS (1) } \\ \text { Implant } & 0 & 2(0.3 \%) & \text { NS (1) }\end{array}$

LARC = Long-Acting Reversible Contraception

IUD = Intrauterine Device 
Table 3. Analysis of changes in post-abortion contraceptive use before and after debate

Post-abortion contraception

$$
\begin{gathered}
\text { Before debate } \\
\mathbf{n}=\mathbf{2 9 1} \\
\%
\end{gathered}
$$

Contraception

$$
\begin{aligned}
& \text { Yes } \\
& \text { No }
\end{aligned}
$$

Type of contraception

Medical
Non-medical

Barrier

Natural

Medical contraception

Oral

LARC

Patch/Ring

Other (Tubal ligation)

Oral contraception

Combined

Progestin only

$$
\begin{gathered}
286(98.2 \%) \\
5(1.7 \%)
\end{gathered}
$$

0

$$
\begin{aligned}
& 5 \%) \\
& 5(1.7 \%)
\end{aligned}
$$

.7\%)

$$
\begin{gathered}
\text { After debate } \quad \text { p-value } \\
\mathbf{n}=\mathbf{6 0 1} \\
(\%)
\end{gathered}
$$

$$
\begin{array}{cc}
585(97.2 \%) & \text { NS }(0.5) \\
16(2.7 \%) & \text { NS }(0.5)
\end{array}
$$

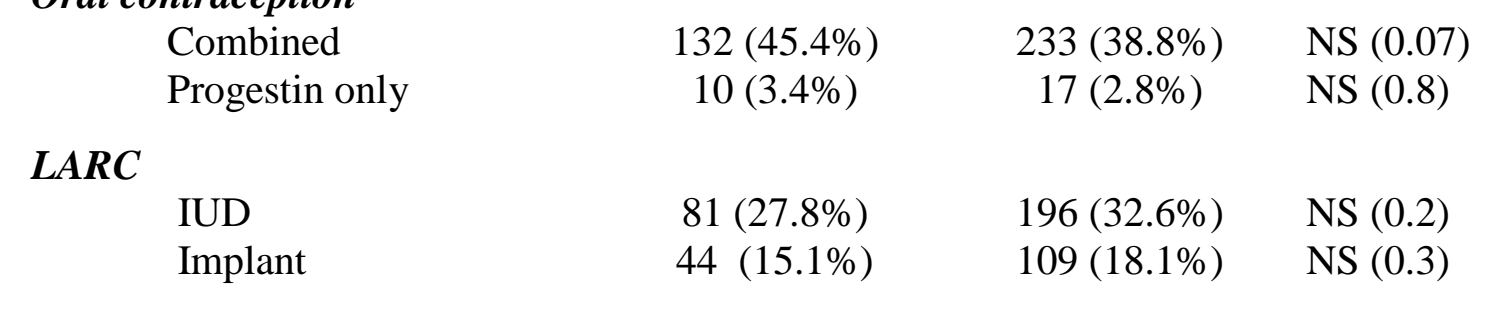

$\begin{array}{ccl}142(48.8 \%) & 250(41.6 \%) & \mathbf{0 . 0 5} \\ 125(42.9 \%) & 305(50.7 \%) & \mathbf{0 . 0 3} \\ 9(3.1 \%) & 11(1.8 \%) & \text { NS }(0.3) \\ 5(1.7 \%) & 8(1.3 \%) & \text { NS }(0.7)\end{array}$

$\begin{array}{cl}574 & \text { NS }(0.5) \\ (95.4 \%) & \text { NS }(1) \\ 11(1.8 \%) & \\ & \text { NS }(0.9) \\ 11(1.9 \%) & \text { NS }(1) \\ 0 & \end{array}$


Table 4. Individual variables associated with LARC users post abortion, before and after debate

\begin{tabular}{lccc}
\hline Variables & Before debate & After debate & p-value \\
\hline & $(n=125$ LARC users $)$ & $(n=305$ LARC users $)$
\end{tabular}

Age (years)

$\begin{array}{llcc}<20 & 17(13.6 \%) & 49(16.1 \%) & \text { NS }(0.6) \\ 20-24 & 18(14.4 \%) & 75(24.6 \%) & \mathbf{0 . 0 3} \\ 25-29 & 27(21.6 \%) & 59(19.3 \%) & \text { NS }(0.7) \\ 30-34 & 28(22.4 \%) & 56(18.4 \%) & \text { NS }(0.4) \\ 35-39 & 28(22.4 \%) & 54(17.7 \%) & \text { NS }(0.3) \\ \geq 40 & 7(5.6 \%) & 12(3.9 \%) & \text { NS }(0.6)\end{array}$

Country of birth

France

$103(83.0 \%)$

$21(16.9 \%)$

Other

\section{Marital status}

Steady partner

Casual partner

$76(61.2 \%)$

$48(45.8 \%)$

Education level

Primary/Middle

school

High school

University

\section{Professional status}

Employed

High school/

Student

Unemployed/

Housewife

\section{Parity}

0

$\geq 1$

Previous
miscarriage
0
$1-2$
$\geq 3$

$81(65.3 \%)$

$12 \quad(9.7 \%)$

$31 \quad(25 \%)$

$29 \quad(23.4 \%)$

$52(42 \%)$

$43(34.6 \%)$ $\geq 3$
$263(86.8 \%)$

$40(13.2 \%)$
NS (0.4)

NS (0.4)

$$
\begin{array}{ll}
139(45.8 \%) & \mathbf{0 . 0 0 5} \\
164(54.1 \%) & \mathbf{0 . 0 0 5}
\end{array}
$$

$123 \quad(40.6 \%)$

NS (0.3)

$98 \quad(32.3 \%) \quad$ NS $(0.07)$

$82(27.1 \%) \quad$ NS $(0.5)$
$127(41.6 \%)$
$178(58.4 \%)$
$198 \quad(64.9 \%)$
$103(33.8 \%)$
$4 \quad(1.3 \%)$

0.017

0.017
$67(53.6 \%)$
$50 \quad(40 \%)$
$8(6.4 \%)$

$\mathbf{0 . 0 3 7}$

NS (0.3)

0.007 


\section{Term of abortion}

5-8 WG

$70(56 \%)$

$181(59.3 \%)$

NS (0.6)

9-14 WG

$55(44 \%)$

$124(40.7 \%)$

NS (0.6)

Smoking

Yes

$72(57.6 \%)$

$182(59.7 \%)$

NS (0.8)

No

NS (0.8)

WG $=$ weeks of gestation 